\title{
Estado de la investigación y bibliografía anotada de la obra literaria de Laura Papo «Bohoreta»
}

\author{
Eliezer Papo* \\ Ben Gurion University, Beer-Sheva
}

El articulo trata de realizar una catalogación de la obra literaria de Laura Papo «Bohoreta», la primera dramaturga femenina de la literatura sefardí. Se ofrece aquí, por primera vez, una lista de todos sus escritos originales (piezas dramáticas, poemas, cuentos breves, novelas y ensayos) conocidos y preservados (en gran parte, inéditos aún). A ello se añade un estado de la cuestión de las traducciones literarias, así como de las recopilaciones de folclore sefardí que ella realizó.

Palabras Clave: Laura Papo «Bohoreta»; judeoespañol; Bosnia; Sarajevo; literatura sefardí; teatro sefardí; romancero; folclore.

The State of the Research and an Annotated Bibliography of the Literary Opus of LaUra PAPO "Bohoreta".- - This article is a survey of the history and the state of the art of the literary opus of Laura Papo "Bohoreta," the first Judeo-Spanish female dramatist. It offers, here, for the first time, a definitive list of all her known and preserved original writings (theater plays, poems, short stories, nouvelles and essays), most of them still unpublished, as well as of her literary translations and recopilations of Sephardic folklore.

Keywords: Laura Papo "Bohoreta"; Judeo-Spanish; Sephardic Jews; Bosnia; Sarajevo; Sephardic Literature; Sephardi Theater; Romancero; Folklore.

Para entender la esencia de la obra literaria de Laura Papo, deberemos delinear los rasgos generales de su personalidad. Por su formación, fue un caso excepcional entre las mujeres sefardíes de nuestros lares. No obstante, su recato impone una sensación de contención en todo lo que ha escrito. En términos generales, no sé si le parecería bien que la presente en la galería de nuestros escritores. No sé si ha publicado algo, a excepción de dos o tres bellos retratos. Pero aún a partir de ellos se puede percibir su talento descriptivo, su gusto desarrollado y su corazón generoso; todas ellas cualidades aparentemente femeninas. El recato ha impuesto la forma de sus obras, los temas y, lo que

\footnotetext{
"eliezerpapo@me.com
} 
es aún más importante, la lengua. Dominaba también el castellano, y por haber estudiado en la Alliance Israélite Universelle (AIU) hablaba francés a la perfección, pero en sus escritos no se nutrió de estas fuentes; su lengua de escritura fue la que traía de su hogar. En general, las mujeres son las guardianas más confiables de nuestra lengua materna. En la lengua de Laura Papo y en su discurso existe cierto esplendor íntimo. Asimimo, la señora Papo es de los nuestros por su concepción de la obra literaria y, en especial, por su estilo.

Kalmi Baruh $^{1}$

\section{ESTADO ACTUAL DE LA INVESTIGACIÓN}

La obra literaria de Laura Papo, Bohoreta (1891-1942) es vasta y dilatada: además de las piezas dramáticas escribió poemas, cuentos breves, novelas y ensayos, todos ellos en judeo-español; asimismo, tradujo textos literarios y recopiló obras del folclore judío sefardí. Su romancero ${ }^{2}$ fue parcialmente publicado por Kalmi Baruh ${ }^{3}$ y Samuel Elazar ${ }^{4}$, y Muhamed

${ }^{1}$ K. BARUH, «Nekoliko pojava lijepe književnosti kod bosanskih Sefarda», en V. Maksimović (priredio), Izabrana djela Kalmija Baruha (Sarajevo 1972), págs. 323-326.

${ }^{2}$ En el legado de Laura Papo hay dos versiones del romancero: la definitiva incluye diez romances; la preliminar contiene los primeros esbozos de siete de diez romances de la versión definitiva, junto a otras seis.

${ }^{3}$ Cf. K. BARUH «Španske romanse bosanskih Jevreja», Godišnjak, «La Benevolencija» - Sarajevo $i$ «Potpora» - Beograd (Sarajevo: Štamparija Menahem Papo 1933), págs. 272288; BARUH, «Nekoliko pojava lijepe književnosti», págs. 300-322. Por su importancia, el artículo de 1933 fue vertido al inglés: «Spanish Ballads of the Bosnian Jews», en JudeoSpanish Ballads from Bosnia (ed. Samuel G. Armistead \& Joseph H. Silverman with the collaboration of Biljana ŠLJIVIĆ-ŠIMŠIĆ) (Philadelphia 1971), págs. 35-58. En este artículo, Kalmi Baruh había publicado siete romances de la colección de Laura Papo: Don Vergile, Morenica (Las tres hermanicas), Labrando estaba la reina, Don Beso, Moricos los mis Moricos, Pasear se ia Silvana, Morena me llaman. Al principio de su artículo, y también al final, Baruh se refiere a Bohoreta diciendo: «Antes de empezar a hablar del tema, queremos destacar que el material ha sido puesto a nuestra disposición por la generosidad de la Sra. Laura Papo, una conocida activista y por lo visto también una de las grandes expertas en el legado sefardí oral en Bosnia» (pág. 301). «Para finalizar, se debe recordar que no se trata de una investigación exhaustiva. Para lograrla habríamos necesitado un trabajo de campo previo y a fondo entre las informantes, yo, como ya lo he dicho, no he realizado esta importante tarea, sino que he usado el material que tenía y el que diera la Sra. Laura Papo, cuya generosidad agradezco en esta ocasión» (pág. 322).

${ }^{4}$ S. ElazAr, El romancero judeo-español (Sarajevo 1987). En su romancero, Elazar incluye los corpus de diversos recopiladores de romances, poemas y cantares escritos por 
Nezirovic ${ }^{5}$ lo ha publicado en su totalidad. Muchos de sus poemas, cuentos y novelas fueron publicados en la prensa judía de Bosnia entre ambas guerras mundiales; últimamente, Nezirović ha publicado un facsímil de las dos versiones del ensayo La mužer sefaradi de Bosna, junto a su traducción al bosnio ${ }^{6}$.

La parte principal de la obra literaria de Laura Papo consiste en sus piezas teatrales, pero lamentablemente ninguna de ellas, ni de sus estampas, ha sido publicada en ningún momento. Cabe destacar que tampoco habían sido escritas para la publicación en libros, sino para la representación en escena. Todas sus piezas dramáticas y todas sus estampas fueron representadas en fechas próximas a su redacción por el elenco de actores aficionados de «Matatja», la asociación de jóvenes trabajadores judíos. Después del Holocausto de los judíos de Yugoslavia, la familia de Laura Papo entregó sus textos autógrafos al Archivo Histórico de Sarajevo?. Desde entonces, su legado literario se encuentra allí, en la caja de cartón núm. O-BP-168, y nunca ha sido objeto de una investigación literaria sistemática y focalizada. Los investigadores yugoslavos (los únicos que conocían de cerca los manuscritos), se han dedicado fundamentalmente a esbozar los rasgos generales de su persona y han mencionado, y en ciertas ocasiones descrito, algunas de sus obras; pero en el ámbito bibliográfico se han realizado esfuerzos más centralizados: la recopilación empieza con

poetas judíos sefardíes en Bosnia. Dentro del romancero, los cantares no figuran según las recopilaciones de las que fueran tomadas, sino ordenados por temas. No obstante, en las notas a pie de página y en las notas finales se puede rastrear la fuente de cada texto y reconstruir los contenidos de las recopilaciones. El romancero de Laura Papo (versión definitiva) está totalmente incluido en el romancero de Elazar, junto a seis poemas de su propia autoría: El namorado i la muerte (pág. 180, poema 194), Madres (pág. 180, poema 195), Prekura de kantar (pág. 181, poema 196), Violetas (pág. 182, poema 197), Alavasiones a la ruda como milisina (pág. 253, poema 253) y Hadras de Pesah, que acompaña a un bosquejo de Laura Papo con el mismo título.

${ }^{5}$ M. Nezirović, «El cancionero de los romances judeo-españoles de Sarajevo de Laura Papo-Bohoreta», Lingüística 26 (1986), págs. 115-130.

${ }^{6}$ M. Nezirović (edicija rukopisa i prevod), Laura Papo Bohoreta: Sefardska žena u Bosni (Sarajevo 2005).

${ }^{7}$ Cf. NeZIrović, «El cancionero de los romances judeo-españoles», pág. 117: «La señora Gordana Kujić, escritora ella misma e hija de la primera donante, la señora Blanka Papo Kujić [sic en Nezirović; su nombre era Blanka Levi Kujić] efectuó, con la ayuda de la señora Rikica Ovadija, una donación más al archivo de la ciudad de Sarajevo, que incluye dos cuadernos manuscritos de Laura Papo, Bohoreta». 


\section{la descripción del legado realizada por Ešraf Čampara, y continuada por Rikica Ovadija ${ }^{9}$, Krinka Vidaković-Petrov ${ }^{10}$, y Muhamed Nezirović ${ }^{11}$.}

${ }^{8}$ E. ČAMPara, Prilog bibliografiji književnog rada Laure Papo / Bohoreta. El inventario de Čampara sirve hasta el presente como único catálogo del legado; fue realizado el 10 de enero de 1963 y tiene 16 páginas mecanografiadas en formato A4, que contienen: a) Un prólogo breve; b) La lista de poemas incluidos en el legado (con una descripción y un resumen), cinco títulos (Violetas, Huanita, Madres, Dotas y Al occasion del jubileo de combate lavoro i succeso); c) La descripción del romancero de Laura Papo (versión definitiva); d) La lista de poemas traducidos por ella, tres títulos (Davičon el hamal, Flor amurčada y La molinera i la karvonera); e) La descripción del cuento «Dulse de rozas», fotocopia de un periódico; f) La lista y resumen de sus piezas dramáticas, con el añadido de notas sobre las fechas de representación y citas de artículos críticos en los periódicos de la época, cinco títulos (Esterka, Avia de ser, Ožos mios, Shuegra ni de baro buena y La pasensia vale тис̌o); g) Una lista de ensayos, dos títulos (La mužer sefardi de Bosna y Hecho hechizo). Parte del material que actualmente se encuentra en el legado no se detalla en la lista; aparentemente se trata de ítems llegados al archivo después de que Čampara preparara la lista. Al describir el cuento «Dulse de rozas», Čampara extrajo sus propias conclusiones de lo escrito por Kalmi Baruh: «Laura Papo escribió otros cuentos, pero no hemos tenido ocasión de leerles y evaluarles», ibíd., pág. 5). Hoy en día, el legado contiene textos autógrafos de una recopilación folclórica (Después de las hadras) y de tres retratos (Tija Rahelona de Sason, Tija Merkada de Jahilo Finci y La paparoza de tio Kako Monteira), que no habían sido detallados en la lista de Čampara. Asimismo, el legado incluye actualmente dos piezas dramáticas que no aparecen en la lista de Čampara: Hermandat y Tiempos pasados. Es posible que Hermandat estuviera antes de Čampara, y que éste decidiera no documentarla porque se trataba de un manuscrito incompleto que empieza sólo en la pág. 10. Čampara no vio tampoco que Avia de ser aparece en el legado en dos versiones; a Renado mi nuera grande, que es una versión preliminar de Shuegra ni de baro buena, la llama «idea»; de este mote surge la impresión de que se trata de hojas sueltas y no de una versión de la pieza teatral. Al cabo de algunos años, Čampara reelaboró su lista publicándola como «Prilog bibliografiji književnog rada Laure Papo / Bohoreta», Jevrejski almanah, 1965-1967 (Beograd 1967), págs. 136-144. En este artículo, Čampara optó por omitir toda la información sobre Renado mi nuera grande.

${ }^{9}$ R. OvadiJa, «Laura Papo Bohoreta», Spomenica 400 godina od dolaska Jevreja u Bosnu i Hercegovinu (Sarajevo 1966), págs. 305-307. Ovadija completa parte de los datos bibliográficos faltantes en Čampara, al menos en todo lo que atañe a los autógrafos conservados actualmente en el archivo. La recopilación folclórica y dos de los tres cuentos que faltan en Čampara aparecen en Ovadija (el cuento «Tia Rahelona de Sason» falta también en ella). Asimismo, la estampa Tiempos pasados, que falta en Čampara, aparece en Ovadija, pero sin ninguna observación con respecto al contenido. Es posible que esta estampa haya sido aportada al archivo por la misma Ovadija, con los dos cuadernos mencionados por Nezirović. Cf. Nezirović, Laura Papo Bohoreta: Sefardska žena. Cabe recordar que Ovadija hace referencia a Renado mi nuera grande y Shuegra ni de baro buena como dos piezas diferentes, aunque se trata de dos versiones de la misma obra. 
La investigación de Nezirović ha hecho avanzar un paso más la finalización de la lista de obras de Laura Papo ${ }^{12}$. No obstante, le ha atribuido la pieza dramática Los aparežos de Hanuka, que no aparece en el legado y que no es mencionada por Čampara ni por Ovadija. En este caso, Nezirović no señaló sus fuentes ${ }^{13}$, pero en apariencia se había basado en un anuncio de Matatja sobre la inminente celebración de Janucá, en el que se señalaba que se representaría también «una opereta en un acto en lengua española», llamada Los aparežos de Hanuka ${ }^{14}$. El anuncio no menciona el nombre del autor, y Nezirović aplicó aparentemente el principio de que «quien se aparta, se aparta de la mayoría» y por eso decidió atribuir también esta opereta a quien había escrito la mayor parte de las operetas y comedias musicales judías sefardíes que se representaban en Sarajevo entre ambas guerras mundiales, es decir, Laura Papo. Pero en el legajo C-41 del

${ }^{10}$ K. Vidaković-Petrov, Kultura španskih Jevreja na jugoslovenskom tlu (Sarajevo 1986). Al final del libro aparece la bibliografía de las secciones y suplementos literarios de los manuscritos judíos en Yugoslavia entre ambas guerras mundiales. La lista no se compromete a presentar todos los artículos difundidos en esas publicaciones periodísticas; no obstante, la mayor parte de los artículos de Laura Papo Bohoreta están incluidos en ella. No se incluyen una estampa («Una manjana de Sukot onde senjor Cappon»), una anécdota («Ajde a mirar peši!») y tres artículos («Parfumes y melodias», «Vakansas vengansas» $\mathrm{y}$ «Nemo propheta in patria»); asimismo, un retrato («Por esto akea vieža no se kižo murir») se atribuyó por error a un tal A. Pinto. En cuanto al corpus de piezas dramáticas, Vidaković-Petrov conocía de cerca los textos autógrafos; se percibe en ella la tendencia a completar la recopilación y la descripción iniciadas por Čampara y Ovadija. Así, por ejemplo, eligió describir precisamente la estampa Tiempos pasados que, como ya se ha señalado, no aparece en Čampara y que en Ovadija es mencionada sin ningún detalle (pág. 107). Asimismo, ha citado (págs. 106-108) extensamente la crítica de Benjamin Pinto sobre el estreno de La madrasta el nombre le abasta. Según el resumen de la crítica, se puede concluir que se trata de otra versión o, quizás, sólo de un cambio de nombre de Hermandat, que no fuera mencionada por Čampara ni por Ovadija.

${ }^{11}$ M. NezIrović, Jevrejsko-španjolska književnost (Sarajevo 1992).

${ }^{12} \mathrm{El}$ retrato, la anécdota y los tres artículos omitidos en la lista de Vidaković-Petrov aparecen aquí con muchos detalles. Asimismo, percibió la atribución errónea del retrato «Por esto akea vieža no se kižo murir». Cf. NEzIrović, Jevrejsko-španjolska književnost, pág. 589, nota 45, si bien cabe señalar que la recopilación folclórica «Salida Pesah» que aparece en Vidaković-Petrov, fue omitida por Nezirović.

${ }^{13}$ Cf. NeZIrović, Jevrejsko-španjolska književnost, pág. 552: «Su obra siguiente, creada exactamente en la misma época, es Los aparežos de hanuka, una comedia musical cómica en un acto».

${ }^{14}$ Jevrejski glas 49 (4-XII-1931), pág. 8. 
archivo histórico de la Unión de nuevos inmigrantes de Yugoslavia «Dr. Yakir Eventov» se encuentra un manuscrito con una estampa llamada Los aparežos y atribuida a «Buki» Demajo ${ }^{15}$. Demajo fue el tercer presidente de Matatja ${ }^{16}$ y uno de los actores del elenco, que actuaba también en las obras de Laura Papo y que había representado varios de sus personajes ${ }^{17}$, pero que nunca se dio a conocer como dramaturgo ni como escritor. La atribución de la obra a Demajo no existe en el original; se trata de un añadido que el curador ha agregado en hebreo. Después de examinarlo, he entendido que esta estampa no es más que una reelaboración teatral del cuento homónimo publicado con el seudónimo literario de Buki ${ }^{18}$, pero que en realidad se trata de otro $«$ Buki» ${ }^{19}$ : Avram Romano ${ }^{20}$.

${ }^{15}$ El manuscrito está escrito en pliegos en formato 28,5 x $23 \mathrm{~cm}$, y tiene once páginas de texto, incluida la portada, escritas en judeo-español, con letra clara y legible en grafía serbo-croata. En la portada se lee el título, pero en la pág. 3 se añade un subtítulo: Akapito aktuel en un akto / antes de Hanuka.

${ }^{16}$ Cf. Y. MAestro, «Qehilat Sarajevo ben šeté Milhamot ha-'Olam», en Toledot Yehudé Yugoslavia. II. Yehudé Croatia u-Bosnia-Herzegovina ba-'idan he-ḥadaš, Z. Locker (ed.) (Jerusalem, Tel Aviv, Haifa 5751 [1991]), págs. 264 y 281; Y. MAestro, Pinqas ha-Qehilot: Yugoslavia (Jerusalem 5748 [1988]), pág. 221 (s. u. «Sarajevo»).

${ }^{17}$ Así, por ejemplo, representó a Benjamin Campeas en Shuegra ni de baro buena (para la crítica a la representación, cf. «Shuegra ni di baro buena», Jevrejski glas 20-X1933; a David Avram en Ožos mios (según una nota de la autora en la lista de personajes en la primera versión del manuscrito; y a uno de los personajes masculinos en Esterka (así lo sabemos por el artículo crítico de Benjamin Pinto sobre la representación en el Teatro Nacional de Sarajevo, publicado en Jevrejski glas 10-X-1930, sin especificar el personaje de Demajo).

${ }^{18}$ BuKI, «Los aparežos», Jevrejski život 33 (14-XI-1924).

${ }^{19}$ El problema de la identidad de Buki, que firmó con este hipocorístico 28 cuentos y artículos en Jevrejski život y en Jevrejski glas, ha quedado resuelto en el libro de NeZIROvić, Jevrejsko-španjolska književnost, pág. 576, según el artículo de K. BARUH, «El judeo-español de Bosnia», Revista de Filología Española 17 (1930), págs. 113-154, contemporáneo y coterráneo de Buki. En este artículo, Baruh reproduce íntegramente el cuento de Buki «Saruča i Hanuča», y sencillamente señala que se trata de una obra del «señor Buki Romano». Basado en esta información, Nezirović rechaza, con razón, la presunción de Vidaković-Petrov de que quien se escondía tras el seudónimo era M. Finci, y corrigió también el error de Avram Pinto (A. PINTo, Jevreji Sarajeva i BiH [Sarajevo 1987], pág. 123), que atribuyó parte de los cuentos de Avram Romano, «Buki», a Avram Finci «Buki».

${ }^{20}$ En el archivo histórico de la Unión de Nuevos Inmigrantes de Yugoslavia se encuentra un manuscrito atribuido, también erróneamente, a Buki Demajo. Se trata de 
La primera investigadora no yugoslava que se ha interesado por las obras teatrales de Laura Papo fue Elena Romero ${ }^{21}$. Al parecer, las fotocopias de ciertos manuscritos de Bohoreta sí llegaron a sus manos, si bien («gracias» a las limitaciones que las autoridades yugoslavas de aquel tiempo ponían a los investigadores ajenos) no llegó a conocer en su totalidad el legado guardado en el Archivo Histórico de Sarajevo, dependiendo en su trabajo de la traducción realizada por Krinka Vidaković-Petrov ${ }^{22}$ de los artículos de Čampara ${ }^{23}$ y Ovadija ${ }^{24}$.

Noče de Hamišoše, que es la reelaboración teatral del cuento «Hamišoše» de «Buki Romano», publicado en Jevrejski život 93 (1926), pág. 1. El rabino Avram Romano, apodado «Buki» y nacido en Sarajevo en 1894, llevaba el nombre de su abuelo el rabino Avram Romano (apodado «Merkado»), uno de los últimos sabios de Sarajevo que alcanzó a gozar de la aureola tradicional de santo y justo. Avram Romano (nieto) fue el rabino de las comunidades de Šamac, Dubrovnik (Ragusa) y Bítola (Monastir). El 11 de marzo de 1943, colaboracionistas búlgaros lo deportaron, junto con los demás judíos de Bítola, a Auschwitz, de donde no regresó. Entre ambas guerras mundiales había publicado en la prensa judía de Sarajevo 28 cuentos breves, algunos de ellos verdaderas obras maestras de la literatura judeo-española en general. Por el amargo destino de la comunidad judía de Yugoslavia y por la posición no muy elevada del cuento breve entre los judíos sefardíes, su obra sólo es conocida por un puñado de lingüistas e investigadores.

${ }^{21}$ E. Romero, El teatro de los sefardíes orientales (Madrid 1979).

${ }^{22}$ Romero, El teatro de los sefardies orientales, § 620: Shuegra ni de baro buena, Romero agradece a Vidaković-Petrov por haber traducido para ella el artículo de Čampara del serbo-croata al español.

${ }^{23}$ Cf. Romero, El teatro de los sefardíes orientales, § 250: Esterka, nota 290, que menciona la fuente de información: «Čampara, Bohoreta, pág. 138, respetamos su ortografía y añadimos acentuación. Toda la información que reseñaremos a continuación está tomada de ese artículo». Por lo tanto, la información de Romero se basa en el artículo de Čampara, «Bohoreta» (cf. nota 8 supra).

${ }^{24}$ Romero conocía también el artículo de Ovadija, y debió resolver contradicciones entre éste y el de Čampara. Como ya se ha señalado, en el artículo de Čampara, «Bohoreta», la pieza Renado mi nuera grande no se menciona en absoluto. Más aún, en su reseña de Shuegra ni de baro buena, Čampara tradujo el nombre judeo-español de la novia, Renado, al nombre serbo-croata Renata, y de esa manera desdibujó aún más las relaciones entre ambas versiones. Cuando a lo antedicho se añade también el hecho de que Ovadija presentó estas dos versiones como dos obras separadas, surge una imagen aún más borrosa y confusa, pero Romero logró solucionar el problema aun sin conocer el material de cerca. En su El teatro de los sefardíes orientales, § 620, Shuegra ni de baro buena, llegó a la conclusión de que «hay puntos de contacto» entre la pieza dramática analizada y otra obra de Laura Papo no incluida en la investigación de Čampara, pero mencionada por Ovadija: «Su título nos hace suponer que que se trata de una trama en la que surgen roces entre 
Desde la publicación de la investigación de Romero, el nombre de Laura Papo ha empezado a penetrar en la conciencia de investigadores que se dedican a la cultura sefardí. Su nombre y los títulos de sus obras eran copiados de lista en lista, pasando de un artículo al otro, sin que muchos fuera de Yugoslavia vieran los escritos propiamente dichos.

En otra ocasión me he ocupado de las opiniones lingüísticas de Laura Papo y de sus decisiones (explícitas e implícitas) respecto a «cuestiones del momento» (escritura, ortografía, fuentes de inspiración y préstamos legítimos para instaurar una expresión novedosa y actualizada del judeoespañol $)^{25}$. En el presente artículo trataré de completar la tarea de registro bibliográfico de los mismos. La lista se divide en cinco categorías: poesía, prosa, drama, crítica, y folclore ${ }^{26}$.

\section{PUBLICACIONES Y ESCRITOS DE LAURA PAPO, «BOHORETA»}

\section{Poesía}

\subsection{Poemas de Laura Papo, «Bohoreta».}

1. «Ožikos de guerko», publicado en Jevrejski život 61 (1925), pág. 3 en grafía serbo-croata con pequeñas influencias castellanas.

2. «A mi nona, Sunha Liačon Šalom», publicado en Jevrejski život 75 (1925), pág. 5, en grafía serbo-croata.

\footnotetext{
la nuera y la suegra, y también coincide el nombre de un personaje (Renado / Renata). También R [Rikica] Ovadija me ha informado que la pieza fue escrita en 1933 en judeoespañol con caracteres latinos, como todas sus obras [de Laura Papo], que fue dedicada al actor Šalom Daniti y que fue representada en Sarajevo en 1933». Y todavía, ante la falta de evidencias sólidas, Romero debía cuidarse de una decisión inequívoca, dejando la cuestión abierta: «De todos modos, en estos momentos no podemos determinar con precisión si se trata de obras diferentes o de dos títulos de una misma obra».

${ }^{25} \mathrm{Al}$ respecto, estoy preparando un artículo «Entre lo deseable y lo posible: la doctrina lingüística de Laura Papo Bohoreta».

${ }^{26}$ Van en cursiva los títulos de los escritos que Laura Papo dejó inéditos (algunos de ellos, publicados posteriormente por otros). Entre comillas, los publicados por ella.
} 
3a. Al occasion del jubileo de combate lavoro i succeso, autógrafo conservado en el legado, versión preliminar, 11 de marzo de 1936, en grafía serbo-croata.

3b. Al occasion del jubileo de combate lavoro $i$ succeso, autógrafo conservado en el legado, versión definitiva, 12 de marzo de 1936, en grafía castellana con muchas desviaciones.

4. El namorado i la muerte, publicado por Elazar, El romancero judeoespañol, pág. 180, en grafía serbo-croata - castellana mezclada ${ }^{27}$.

5. «Madres», publicado por Elazar, El romancero judeo-español, pág. 180, nueve estrofas de cuatro versos, autógrafo conservado en el legado y una copia mecanografiada, una única hoja $\mathrm{A} 4$, ambas en grafía serbo-croata.

6. «Prekura de kantar», publicado por Elazar, El romancero judeo-español, pág. 181, en grafía serbo-croata.

7. «Violetas», publicado por Elazar, El romancero judeo-español, pág. 182, en grafía serbo-croata. La estructura del cantar no es clara ${ }^{28}$.

8. «Alavasiones a la ruda como milisina», publicado por Elazar, El romancero judeo-español, pág. 253, en grafía serbo-croata ${ }^{29}$.

9. Huanita, una hoja suelta A4 mecanografiada, sin fecha, ocho estrofas de cuatro versos, en grafía serbo-croata.

\subsection{Traducciones de poemas de otros autores}

1. «Lem Edim», poema de Jovan Jovanović Zmaj traducido por Bohoreta y publicado en Jevrejski život 159 (1927), pág. 3, en grafía serbo-croata con pequeñas influencias castellanas.

${ }^{27}$ Elazar definió este cantar como obra de Laura Papo. Es probable que se trate del cantar que había escrito según los motivos de una canción popular, pero también es posible que se trate de una canción popular que había recopilado.

${ }^{28}$ En el legado se encuentra una hoja suelta en formato A4, y una copia mecanografiada del cantar, en grafía serbo-croata.

${ }^{29}$ Elazar adscribió este cantar a Laura Papo. Es posible que se trate de una reelaboración suya de una conocida copla del 15 de Šebat, pero también es posible que sea una versión desconocida de la copla, y que Bohoreta sólo la haya recopilado. 
2. Flor amurćada, poema del autor croata Gustav Krklec traducido por Bohoreta, autógrafo conservado en el legado, una hoja suelta. Junto al poema se lee la fecha 10 de diciembre de 1932. En grafía serbo-croata.

\subsection{Recopilaciones de romances}

1a. Romancero de Laura Papo, «Bohoreta», versión preliminar. Autógrafo conservado en el legado; 62 páginas en un cuaderno de formato de $25 \times 21 \mathrm{~cm}$. Judeo-español en grafía castellana con muchas desviaciones, y alemán. Entre otras cosas, este cuaderno incluye la recopilación preliminar de 13 romances recogidos de cuatro informantes. Siete de ellos ${ }^{30}$ fueron incluidos en la versión definitiva del romancero de Laura Papo y publicados en diversas ocasiones ${ }^{31}$ : otros seis ${ }^{32}$ fueron publicados por Nezirović en 1986. Junto a algunos romances hay algunas notas sobre las informantes ${ }^{33}$ y la fecha de recopilación ${ }^{34}$. En otros romances se añaden comentarios marginales en lo que parecen notas a una primera edición ${ }^{35}$.

1b. Romancero, versión definitiva que sólo incluye ocho romances ${ }^{36}$. Como se ha dicho, siete romances ya habían sido publicados por Baruh en 1933; el romancero completo fue publicado por Nezirović

${ }^{30}$ Lavrando estava la reyna, Silvana, Morenica (Las tres hermanicas), Mauricos los mis Mauricos, Segadores, La doncella de Marsilla, Carcelero.

${ }^{31} \mathrm{Cf}$. a continuación, inciso $1.3,1 \mathrm{~b}$.

${ }^{32}$ La hermosica, Paseando se Rondale, El raptor pordiosero, Calbagata de Peranzueles, Don Bueso y su hermana, Hermanas reina y cautiva.

${ }^{33}$ Así, por ejemplo, en la pág. 2 se encuentra el romance Segadores sin título, y abajo el nombre completo de la informante, Gjoja Levi Teodorus, con una nota posterior, «schön geschrieben».

${ }^{34}$ Así, por ejemplo, en la pág. 3, junto al título Leila se lee la fecha 17 de enero de 1917, pero el romance en sí no fue registrado allí, sino en la pág. 47.

${ }^{35}$ Así, por ejemplo, en la pág. 1, junto al romance Paesear ia Silvana se lee el nombre completo de la informante, escrito en bastardilla y con otro lapicero, y junto a él una nota en alemán, «schön geschrieben».

${ }^{36}$ Lavrando estava la reyna, Don Virgile, Silvana, Morenica (Las tres hermanicas), Don Beso, Mauricos los mis Mauricos, Morena me yaman, Segadores, La doncella de Marsilla, Carcelero. 
en 1986. En 1987 Elazar publicó todos las romances que aparecen en el romancero de Laura Papo, «Bohoreta», pero dispersos y no en un solo volumen ${ }^{37}$.

2. Carta de 1928, una página y anexo (en total tres páginas), con el romance Amadi. La carta (sin el anexo) fue publicada por Nezirović en 1986. Autógrafo conservado en el legado, con fecha del 25 de agosto de 1928. La carta fue escrita en París, en castellano.

\section{PROSA}

\subsection{Novelas}

1. «Morena», cuento en episodios, publicado en Jevrejski život en ocho capítulos: a) núm. 35 (1924), pág. 2; b) núm. 38 (1924), pág. 3; c) núm. 41 (1925), pág. 3; d) núm. 44 (1925), pág. 5; e) núm. 46 (1925), pág. 3; f) núm. 48 (1925), pág. 3; g) núm. 51 (1925), pág. 3 ; h) núm. 52 (1925), pág. 3, en grafía serbo-croata, con pequeñas influencias castellanas.

2. «Linda», publicada en Jevrejski glas 19 (1928), pág. 4, con el subtítulo de Rikordo de Oriente, en grafía serbo-croata, con pequeñas influencias castellanas.

3. «Dulse de rozas», publicada en Jevrejski glas 31 (1932), págs. 2-3, en grafía serbo-croata.

\subsection{Retratos}

1. «Zekky Effendi eine Erinnerung» ('recuerdos de Zekky Effendi'), publicado en Bosnische Post, 31-XII-1916"

\footnotetext{
${ }^{37}$ El autógrafo se encuentra en el legado, pliego, 16 páginas en formato $24,5 \mathrm{x}$ $19 \mathrm{~cm}$, en grafía castellana con muchas desviaciones. Según las notas del manuscrito, el romancero se preparó el 29-31 de enero de 1917. Al principio incluía sólo nueve romances, pero al final se agregó también Carcelero. Todos los datos faltantes en la versión de trabajo fueron completados en esta versión. Al final de cada romance se lee el nombre completo, la edad y, a veces, el lugar de residencia de la informante.

${ }^{38}$ En las págs. 39-46 del cuaderno de recopilaciones se encuentra el borrador de un artículo manuscrito de la autora, con el título de Zekky-effendi Rafaelović eine Skizze von Laura Papo Bohoreta ('Zekky-Effendi Rafaelović, bosquejo de Laura Papo Bohoreta'). Fecha de redacción: 21 de diciembre de 1916.
} 


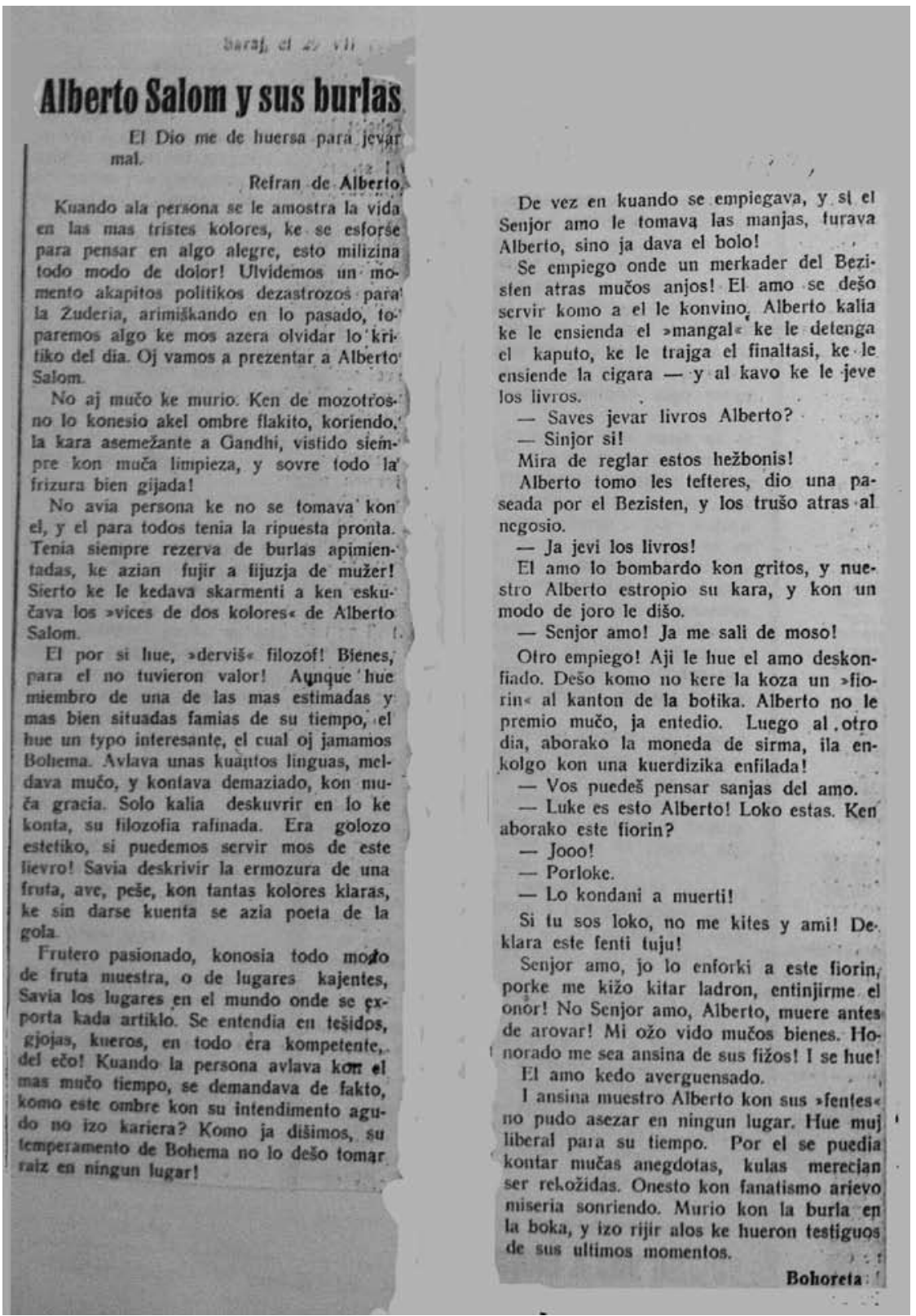

FIGURA 1: «Alberto Salom y sus burlas», Jevrejski glas 31 (1936), pág. 8 
2. «Por esto akea vieža no se kižo murir», publicado en Jevrejski glas 30 (1929), págs. 9-10 en grafía serbo-croata, con pequeñas influencias castellanas.

3. «Una manjana de Sukot onde senjor Cappon», recuerdos personales del Hajam Abraham Aharon Cappon al cumplirse dos años de su muerte, publicado en Jevrejski glas 47 (1931), pág. 6, en grafía serbo-croata.

4. «Tia Rahelona de Sason», publicado en Jevrejski glas 22 (1932), pág. 6 , en grafía serbo-croata ${ }^{39}$.

5. «La paparoza de tijo Kako Monteira», publicado en Jevrejski glas 25 (1936), pág. 8, en grafía serbo-croata, con pequeñas influencias castellanas $^{40}$.

6. «Tija Merkada de Jahilo Finci», publicado en Jevrejski glas 14-15 (1936), pág. 16, con el título In memoriam, en grafía serbocroata $^{41}$.

7. «Alberto Salom y sus burlas», publicado en Jevrejski glas 31 (1936), pág. 8, en grafía serbo-croata, con pequeñas influencias castellanas.

\subsection{Anécdotas}

1. «Pasa para ariva», publicada en Jevrejski glas 159 (1927), pág. 3, en grafía serbo-croata.

2. «Ajde a mirar peši!», publicada en Jevrejski glas 18 (1936), pág. 6, en grafía serbo-croata

\footnotetext{
${ }^{39}$ Autógrafo, cuatro hojas sueltas en formato $34 \times 21 \mathrm{~cm}$, se encuentra en el legado. Al principio de la primera página se lee la fecha: 22 de mayo de 1932. En el legado se conserva también una copia mecanografiada, dos hojas en formato A4. En ambas fuentes la grafía es serbo-croata.

${ }^{40}$ Autógrafo, tres hojas sueltas en formato $34 \times 21 \mathrm{~cm}$, se encuentra en el legado. $\mathrm{Al}$ principio de la primera página se lee la fecha: 3 de mayo de 1936. Al final del texto se señala la fecha 10 de mayo de 1936. La grafía es serbo-croata con ligeras influencias castellanas.

${ }^{41}$ Autógrafo, dos hojas sueltas de un cuaderno de cálculo, en formato $32 \times 20,5 \mathrm{~cm}$, se encuentra en el legado. Al principio de la primera página se lee la fecha: 29 de mayo de 1936. La grafía es serbo-croata.
} 


\begin{tabular}{|c|c|}
\hline 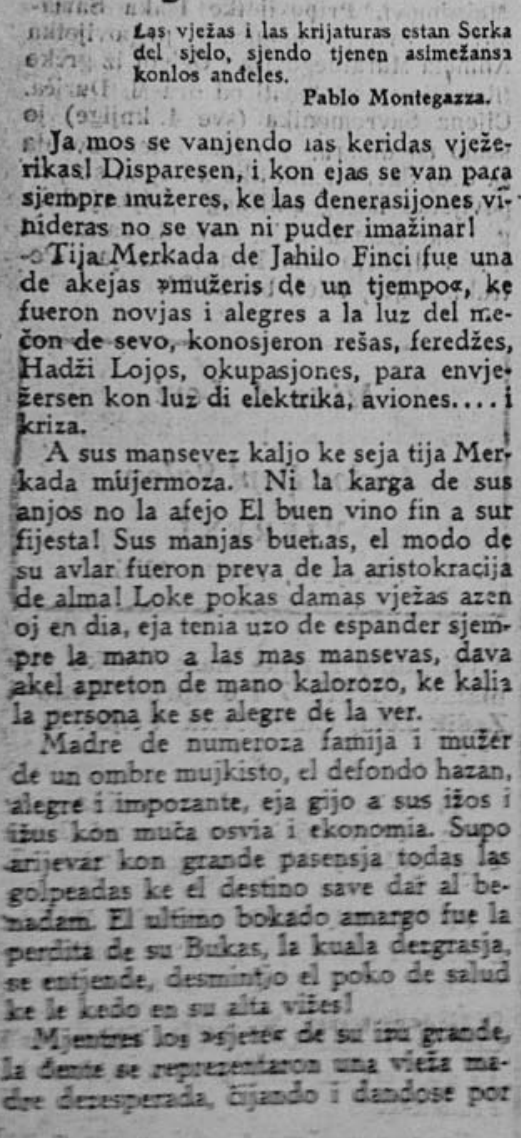 & 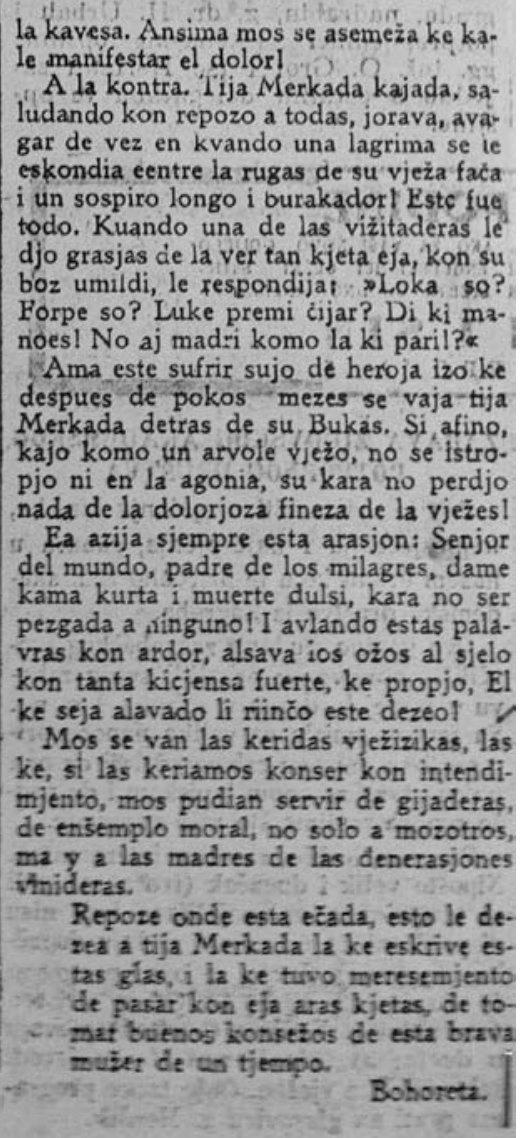 \\
\hline
\end{tabular}

FiguRa 2: «Tija Merkada de Jahilo Finci», Jevrejski glas 14-15 (1936), pág. 16.

\section{DRAMAS}

\subsection{Dramas sociales}

1. Esterka, autógrafo conservado en el legado, 131 páginas de cuaderno en formato 34 x $21 \mathrm{~cm}$. En la primera página hay una lista de accesorios para el primer acto. La portada de la pieza aparece sólo en la segunda página. El primer acto, a continuación, no tiene una portada 
por separado e incluye 39 páginas de texto; el segundo acto tiene 41 páginas (la portada, 38 páginas de texto y dos páginas con la lista de accesorios), y el tercer acto, 49 páginas (47 de texto, sin portada y dos páginas con la lista de accesorios). En la portada general, debajo del título, hay un subtítulo: Ritrato social de muestros dias en 3 actos, que no se repite en las primeras páginas de ninguno de los actos. Más aún, en la primera página del segundo acto aparece otro subtítulo, Kantes, romanses, melodias de Oriente. En la portada general aparece la fecha 24 de julio de 1929. La redacción del primer acto finalizó el 16 de diciembre de 1929, la del segundo el 29 de diciembre de 1929 y la del tercero el 12 de julio de 1930. La primera página de los tres actos empieza con el bosquejo de la escena y las observaciones de la autora. La lista de personajes aparece sólo en la portada general: «Penserios dedicados a mi muy querida madre, mi mamile, que la nombravan Esterka cuando era joben, su hija grande Bohoreta» ${ }^{42}$.

2a. Renado mi nuera grande, autógrafo conservado en el legado, versión preliminar de Shuegra ni de baro buena, 80 páginas de cuaderno en formato 34 x $21 \mathrm{~cm}$. La obra tiene una portada general, una introducción (tres páginas) y tres actos: el primero de 24 páginas, el segundo de 24 y el tercero de 28. En la portada general, el título de la obra es el antes mencionado; al principio del segundo acto y del tercero hay una ligera modificación: Reinado mi nuera la grande. En la portada general y al principio del segundo acto aparece también un subtítulo: Estampa de muestros dias. En la portada general la fecha es el 12 de septiembre de 1932. La redacción del primer acto finalizó el 19 de septiembre de 1932; la del tercer acto empezó el 4 de junio de 1933 y finalizó el 22 de junio de 1933. La dedicatoria es: «Dedicado al bravo y joben artista Šalom, el que sabe hacer reir y llorar al publico sefardi de Saraj que mucho lo quere».

\footnotetext{
${ }^{42}$ Cabe mencionar que esta pieza se encuentra en el legado también en una copia mecanografiada, con correcciones a las erratas del manuscrito de la autora. El corpus contiene 84 páginas en formato $\mathrm{A} 4$, al principio aparece la lista de accesorios para el primer acto. La portada general de la obra aparece en la segunda página. El primer acto que le sigue no cuenta con una portada por separado, y tiene 24 páginas de texto. Los dos últimos actos empiezan con la lista de accesorios. El segundo acto tiene 26 páginas y el tercero, 30 páginas de texto. El subtítulo, la dedicatoria y las fechas de la portada general y al final de cada acto son idénticos a los del manuscrito. El subtítulo secundario del manuscrito, al principio del primer acto, no se encuentra en este corpus.
} 
2b. Shuegra ni de baro buena, autógrafo conservado en el legado, versión definitiva (como se ha señalado, la versión preliminar tiene otro nombre), 90 páginas de cuaderno en formato $34 \times 21 \mathrm{~cm}$. La obra tiene tres actos, ninguno de ellos tiene una portada por separado. El manuscrito empieza con una portada general y termina con la lista de accesorios para toda la representación. El primer acto tiene 32 páginas; el segundo, 29 y el tercero, 27. En la portada general aparecen dos fechas: la de iniciación de la redacción, 12 de septiembre de 1932 y la de finalización, 21de junio de 1933, pero al final del tercer acto aparece otra fecha de finalización: 7 de julio de 1933. También al final del segundo acto aparece una fecha posterior a la fecha de finalización señalada en la portada: 3 de julio de 1933, a la que se añaden dos palabras entre paréntesis, «at home» ('en casa') ${ }^{43}$. En la portada general aparece un subtítulo, Pedaso en tres aktos, retrato social de muestros dias, y una dedicatoria, «Dedicado a Šalom Daniti».

3. Hermandat, autógrafo conservado en el legado, 69 páginas de cuaderno en formato 34 x $21 \mathrm{~cm}$. Manuscrito incompleto: empieza en la página 10, con una paginación original y uniforme (sin separación entre los actos), y termina en la página 76. Las dos últimas páginas no están numeradas ${ }^{44} \mathrm{y}$ tampoco la página con el bosquejo del escenario al principio del segundo acto. Además de eso, hay errores en la paginación: hay dos páginas 39 y dos páginas $57^{45}$. La obra tiene tres actos: el primero de 27 páginas; el segundo de 24 (el diseño del escenario y 23 páginas de texto) y el tercero de 26 . Al principio de la página 11 aparece la fecha 14 de noviembre de 1935; al final del primer acto aparece la fecha del 31 de julio de 1935; al final del segundo, el 4 de agosto de $1935 \mathrm{y}$ al final del tercero el 7 de agosto de 1935.

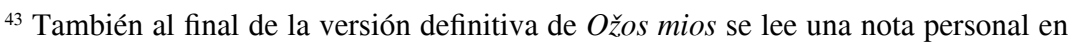
inglés, «It snows» ('nieva').

${ }^{44}$ En la primera se lee Romance du moyen age, y empieza con «Sur son coursier, fier et sauvage», cuya relación con la pieza no es clara (al final del romance se lee también la fecha: 9 de abril de 1935). En las dos hay listas de accesorios para cada acto por separado.

${ }^{45}$ La paginación que aparece en el corpus no es original, sino posterior a la redacción de las piezas. Aparentemente, Čampara es responsable de ella. No obstante, he optado por seguirla (para evitar confusiones), con leves correcciones: la página no numerada que sigue a la pág. 39 la he numerado 39b, y he hecho lo mismo con la página no numerada que sigue a la pág. 57. A las dos últimas páginas he asignado los números 77 y 78; y a la página con el croquis del escenario la he numerado, como ya se señalado, $27 \mathrm{~b}$. 


\subsection{Obras dramáticas de costumbres}

1a. Ožos mios, autógrafo conservado en el legado, versión preliminar, 58 páginas de cuaderno en formato $34 \times 21 \mathrm{~cm}$. La obra tiene tres actos, en el manuscrito falta el segundo acto; empieza con el resumen del primer acto (dos páginas) y pasa al acto propiamente dicho. El primer acto tiene 32 páginas y el tercero, 33. Ningún acto tiene portada. Al principio del resumen, junto al título hay también un subtítulo, «Onde estan akeos dias», que no se repite al comienzo de los actos. Al principio de la pág. 1 se lee la fecha 7 de julio de 1931, y al pie de la pág. 68, 17 de agosto de 1931. En la página inicial del primer acto (pág. 3) aparece el título y un subtítulo, Pedaso de folklor sefardi en tres aktos, el bosquejo de la escena con notas y la lista de personajes (once); junto a nueve personajes aparecen los nombres de los actores que los representarán, y junto a los otros dos hay observaciones de carácter: «fečindoza»y «avagaroza». En la pág. 64 se lee la lista de accesorios para la representación.

1b. Ožos mios, autógrafo conservado en el legado, versión definitiva, 107 páginas de cuaderno en formato 34 x $21 \mathrm{~cm}$. La obra tiene tres actos; en los dos primeros no hay portada, en el tercero sí la hay. El primer acto tiene 34 páginas; el segundo, 39, y el tercero, 40. La primera página del manuscrito no tiene ninguna fecha, pero al final de la obra se señala el 14 de septiembre de 1931. En la primera página de cada acto hay un subtítulo, Pedaso de teatro de folklor sefardi en Bosna en tres aktos ${ }^{46}$. Al final del acto figura la lista de accesorios para la representación. Hay una dedicatoria: «Dedicados penserios y membransas a muestras nonas».

\subsection{Estampas de costumbres}

1a. Avia de ser, manuscrito, autógrafo conservado en el legado, versión preliminar, 14 páginas de cuaderno en formato 34 x $21 \mathrm{~cm}$. El manuscrito no tiene portada, el título y dos subtítulos se encuen-

\footnotetext{
${ }^{46}$ En el subtítulo del segundo acto se omiten las palabras «de teatro», y en el subtítulo del tercer acto se omiten las palabras «de Bosna».
} 
tran al principio de la primera página. El primer subtítulo es Evocacion y el segundo, Stampa, scena de la vida de un tiempo. Al principio de la pág. 1 figura la fecha: 18 de febrero de 1930, y al pie de la pág. 14, el 23 de febrero de 1930. La versión preliminar termina en la pág. 12, y al pie de la misma dice: «Fin, 20.2.1930, Bohoreta». Las dos últimas páginas se añadieron posteriormente. En la pág. 1 se lee la descripción del escenario y la lista de personajes (tres). Junto a cada uno se detalla la edad; junto a dos nombres aparecen también los nombres de los actores que los representarán.

1b. Avia de ser, manuscrito, autógrafo conservado en el legado, versión definitiva, 22 páginas de cuaderno en formato 34 x $21 \mathrm{~cm}$. El manuscrito no tiene portada; el título y dos subtítulos se encuentran al principio de la primera página. El subtítulo es Escena de la vida de un tiempo kon romansas en 1 akto. Al principio de la primera página figura la fecha: 18 de febrero de 1930, y al pie de la última página (26), el 23 de febrero de 1930. En la primera página se lee también la descripción del escenario y la lista de (tres) personajes. Al final de la obra se agrega una escena que no estaba planeada de antemano, en la que aparecen dos personajes (el padre y el señor Liačo), no detallados en la lista de personajes original.

2. La pasensia vale тис̌o, manuscrito, autógrafo conservado en el legado, 20 páginas de cuaderno en formato $34 \times 21 \mathrm{~cm}$. El manuscrito no tiene portada, al principio de la primera página se encuentran el título y un subtítulo, Estampa del folklor del tiempo del turko en un akto. Debajo del subtítulo se ve un dibujo de la escena, la lista de personajes y la fecha, 7 de abril de 1934. En la última página se lee la lista de accesorios para la representación y la fecha de finalización de la redacción, 10 de abril de $1934^{47}$.

3. Tiempos pasados, manuscrito, autógrafo conservado en el legado, 25 páginas de cuaderno en formato $34 \times 21 \mathrm{~cm}$. El manuscrito no tiene portada, al principio de la primera página se encuentran el título y

\footnotetext{
${ }^{47}$ Esta estampa no es sino el extracto de la trama de Ožos mios. Como, según esta obra, se han hecho representaciones independientes, y también por la gran distancia que media entre ambas piezas, cabe ver esta estampa como una obra separada y no como la segunda versión de la primera pieza.
} 
un subtítulo simples, Estampa, Un akto, y la fecha 14 de noviembre de 1939. Debajo de ellas se observa el bosquejo del escenario y su descripción. En la página siguiente se lee la lista de personajes y los nombres de los actores que los representarán. En la última página aparece la fecha: 19 de noviembre de 1939.

\subsection{Piezas cortas}

1. «Hadras de Pesah», autógrafo conservado en el legado, dos hojas sueltas en formato $32 \times 20 \mathrm{~cm}$, sin título, en grafía serbo-croata con ligeras influencias castellanas. Publicado también en Jevrejski život $151(1927)^{48}$, y posteriormente en Elazar ${ }^{49}$.

2. La molinera y la karvonera, en el legado se conserva un autógrafo fechado el 28 de noviembre de 1935, con el poema/ la pieza corta acompañado por el subtítulo Kantika francesa adaptada en espanjol por Laura Papo Bohoreta. Aparentemente se trata de una versión tardía, porque según el testimonio de Kujić ${ }^{50}$, la canción fue traducida en los años que siguieron a la Primera Guerra Mundial, a pedido de «La Benevolencia» como base para la pieza corta ${ }^{51}$ representada cerca de su redacción.

3. Dotas $^{52}$, mecanografiado, cinco páginas, formato $34 \times 21 \mathrm{~cm}$ en grafía serbo-croata; al final de la obra, junto a la firma aparece la fecha del 12 de enero de 1939.

4. Davičon el hamal, subtítulo: Motivos de un poema de Heine, autógrafo, dos páginas, formato $20 \times 15 \mathrm{~cm}$, en grafía serbo-croata, sin fecha.

\footnotetext{
${ }^{48}$ Con el añadido de una nota de la redacción: «Una kantika, tomada de la ovra 'adras de Pesah' de la onorada senora Laura, đugada kon grande sukceso las otras semanas en el Glorijin Dom i en el Union. La musika es la del kante populare italiano 'Spazzacamino'».

${ }^{49}$ ElazAR, El romancero judeo-español, pág. 210 canción 215.

${ }^{50}$ El olor de la lluvia (nota 29 supra), pág. 67.

${ }^{51}$ Por eso se decidió su lugar en la lista de piezas cortas, y no en la lista de canciones.

${ }^{52}$ Čampara definió a esta obra como una canción, pero en realidad se trata de una pieza corta escrita para «La Gloria» y representada en una de sus fiestas.
} 


\section{CRÍTICA}

\subsection{Ensayos}

1. Hecho hechizo, autógrafo conservado en el legado, pliego, 32 páginas (incluida la página de la portada) en formato 34 x $21 \mathrm{~cm}$, en grafía serbo-croata - castellana mezclada. En la página de la portada se lee la fecha: 23 de noviembre de 1927. En la pág. 31 se lee la fecha: 25 de junio de 1928.

2a. La mužer sefardi de Bosna ${ }^{53}$, versión preliminar, autógrafo conservado en el legado, cuaderno de 20 x $17 \mathrm{~cm}, 69$ páginas escritas (no hay portada ni índice) en grafía serbo-croata - castellana mezclada. En la primera página se lee la fecha: 3 de julio de 1931; en la última, la fecha es 7 de julio de 1931. Nezirović ha publicado el facsímil del manuscrito.

2b. La mužer sefardi de Bosna, versión definitiva, autógrafo conservado en el legado, 97 páginas de cuaderno en formato $33,5 \times 21,5 \mathrm{~cm}$, incluida la página de la portada y el índice al final del pliego, en grafía serbo-croata con ligeras influencias castellanas. En la página de la portada hay una dedicatoria: «A la 'Benevolencia', valerosa amiga del progreso - Laura Papo (Bohoreta)». En la primera página se señala la fecha: 18 de diciembre de 1931; en la página $95 \mathrm{se}$ lee la firma de Bohoreta y junto a ella la fecha: 9 de ab de 5692, 11 de agosto de 1932. Nezirović ha publicado el facsímil del manuscrito con el añadido de la traducción al bosnio.

\subsection{Artículos periodísticos}

1. «Die Spanolische Frau» ('La mujer sefardí'), en alemán ${ }^{54}$, publicado en Bosnische Post 287 (17-XII-1916), pág. 8; es el artículo de respuesta a «Die Südslavische Frau in der Politik» ('La mujer eslava

${ }^{53}$ En las págs. 49-53 del cuaderno de recopilaciones se encuentra un registro preliminar (en alemán) de un ensayo antropológico-social escrito en judeo-español. Su título es Die Jüdische Frau y gran parte de los temas detallados en él son analizados en la versión definitiva del ensayo.

${ }^{54}$ Como ya se ha dicho, en los años noventa se incorporó al legado un cuaderno de recopilaciones, autógrafo, con la versión de trabajo del artículo (págs. 11-21). 
del sur en la política') de Jelica Bernadzikowska Belović, publicado una semana antes en el mismo periódico.

2. «Madres», publicado en Jevrejski život 34 (1924), pág. 3, en respuesta al cuento «Dos vizinas in el kortižo» de Avram Romano, Buki, publicado en el número anterior del mismo periódico; en grafía serbo-croata.

3. «Parfumes y melodías», artículo sobre el concierto del jubileo de «La lira», publicado en Jevrejski život 151 (1927), pág. 3, en grafía serbo-croata con ligeras influencias castellanas.

4. «Vakansas vengansas», artículo sobre los grupos juveniles que organizaban excursiones durante las vacaciones de verano, publicado en Jevrejski život 155 (1927), págs. 2-3, en grafía serbo-croata con ligeras influencias castellanas.

5. «Nemo propheta in patria», introducción a las traducciones de Bohoreta de la poesía serbo-croata, publicado en Jevrejski život 159 (1927), pág. 3, en grafía serbo-croata con ligeras influencias castellanas.

\subsection{Traducciones de artículos}

«La haluca», artículo de la Dra. Nadia Stein traducido del alemán, publicado en Narodna židovska svijest 158-159 (1927), págs. 1-2, en grafía serbo-croata.

\section{FolCLORE}

\subsection{Costumbres de las festividades}

1. «Salida Pesah», publicado en Jevrejski život 57 (1925), pág. 4, en grafía serbo-croata con ligeras influencias castellanas.

2. Duspues de las hadras, manuscrito, autógrafo conservado en el legado, dos hojas sueltas de un cuaderno de cálculo, en formato $32 \mathrm{x}$ $20,5 \mathrm{~cm}$, en grafía serbo-croata con ligeras influencias castellanas. 


\subsection{Juegos}

«Uno de los đugos ke se estan desparesiendo», publicado en Jevrejski život 124 (1926), pág. 3, en grafía serbo-croata con ligeras influencias castellanas ${ }^{55}$.

Recibido: 27/09/2011

Aceptado: 12/04/2012

\footnotetext{
${ }^{55}$ Este articulo está firmado con la mayúscula 'B'. De su contenido y también de su lenguaje podríamos concluir que la inicial sirve de abreviación del seudónimo (Bohoreta). Laura Papo no firmaba todos sus escritos de la misma manera. En algunas ocasiones, utilizaba un seudónimo, y en otras su nombre y apellido e, incluso, otras veces combinando ambos. Si este artículo fue verdaderamente escrito por ella, entonces tendríamos un ejemplo de su firma con la inicial del seudónimo.
} 